Article

\title{
Grease Aging Effects on Film Formation under Fully-Flooded and Starved Lubrication
}

\author{
Tiago Cousseau $^{1, *}$, Beatriz Graça ${ }^{1}$, Armando Campos ${ }^{2}$ and Jorge Seabra $^{3}$ \\ ${ }^{1}$ INEGI, Institute of Science and Innovation in Mechanical and Industrial Engineering, Dr. Roberto \\ Frias Street, 400, 4200-465 Porto, Portugal; E-Mail: bmg@ @e.up.pt \\ ${ }^{2}$ ISEP, Superior Engineering Institute of Oporto, Dr. António Bernardino de Almeida Street, 431, \\ 4200-465 Porto, Portugal; E-Mail: ajc@isep.ipp.pt \\ ${ }^{3}$ FEUP, Faculty of Engineering of Porto University, Dr. Roberto Frias Street, 4200-465 Porto, Portugal; \\ E-Mail: jseabra@fe.up.pt
}

* Author to whom correspondence should be addressed; E-Mail: tiagoegm @ gmail.com;

Tel.: +55-11-30919855.

Academic Editors: Jose M. Franco and Jesus F. Arteaga

Received: 25 December 2014 / Accepted: 25 February 2015 / Published: 9 April 2015

\begin{abstract}
Several film thickness measurements were performed with three fresh and aged lubricating greases, their base and bled oils under a wide range of operating conditions using a ball-on-disc test rig with optical interferometry. The analysis of the film thickness measurements is in agreement with the observations of several authors and adds some important aspects regarding separate film properties in EHL contacts. At full film lubrication and moderate to high speeds, the bled oil showed a similar behavior of its lubricating greases. At fully-flooded condition, low speeds and thin films, it was observed that the thickener lumps play a major role on film formation, overcoming the bled oil effects. A relationship between thickener type and film formation was evidenced. The same trends were observed under starved lubrication, where the thickener type that contributes the most to locally increase the film thickness follows the order of $\mathrm{PP}>\mathrm{Ca}>\mathrm{Li}$. The aging process of the greases was shown to change their rheological response in different manners-softening or hardening - depending on the grease formulation. Grease aging increased the film thickness under fully-flooded and starved lubrication, regardless of the level of degradation.
\end{abstract}

Keywords: aging; grease; bled oil; thickener; film formation 


\section{Introduction}

The accurate prediction of EHL film thickness, under actual operating conditions and for a wide variety of lubricants, is extremely important to ensure controlled separation of the mating surfaces, because it leads to an increase of the energy efficiency and useful life service of mechanical components.

In the case of oil lubrication, the films can be reasonably predicted using the classical EHL theory, although there is an endless discussion on how to obtain the pressure-viscosity coefficient, which is extremely important for accurate predictions. However, in the case of grease lubrication, it is much more difficult, because several aspects play a role, such as oil bleeding, oil flow, starvation, aging, thickener content, etc. [1].

Over the last fifty years, both experimental and numerical tools have been significantly improved to predict grease film thickness, and many researchers have presented film thickness formulas based on their numerical and experimental analysis. Most of the published work concerns fully-flooded lubrication, although the starved condition has been studied, as well.

Nowadays, the current practice consist of estimating grease film thickness based on the grease's base oil properties, which was shown to work quite well for lithium greases, but incorrectly for some operating conditions and grease types [2,3].

Beside the significant number of equations available to predict grease film thickness [2,4-7], they all have some drawbacks. From the author's point of view, there is not enough experimental evidence to support these formulas and theories. Nowadays, there is common agreement that initially, the film can be predicted using the grease viscosity, but as soon starvation occurs, the film will primarily be determined by the base oil viscosity [1]. The former statement is based on experimental evidence that thickener lumps enters the contact [8-10], and the latter is based on experimental tests that suggest that base oil approaches the grease performance at high shear rheometry [11]. However, in these cases, the experiments were performed under a limited range of operating conditions, but applied as a general rule. For example: (i) the thickener was observed passing through the contact only in experiments performed at low speeds; (ii) grease and base oil friction performances were shown to be similar in tests performed in 1975 and in the extrapolation of high shear rheology, but actual film thickness measurements and numerical models have shown that grease does not perform like its base oil $[2,3,12,13]$; (iii) high shear and high pressure rheometry has not been applied to lubricating greases to attest that grease behaves like its base oil, etc.

Additionally, it is known that the grease properties might change drastically in the very beginning of its life [1]. The lack of consensus on how grease lubricates the contact and the uncertainty about the rheological properties of the lubricant film along the grease's life [14,15] lead most of the research efforts to understand the grease film composition and formation.

This calls for new approaches to characterize the grease lubrication mechanisms and the properties of the grease active lubricant during its life in order to relate this to its performance. In this regard, three different greases were analyzed to understand the whole of their thickener type, oil nature, rheological properties and chemical composition on their tribological response as fresh and when aged. 


\section{Experimental Section}

\subsection{Tested Greases}

Three fully-formulated lubricating greases, their base and bled oils were analyzed. The greases were named according to their chemical formulation (i.e., thickener + base oil): LiM1 is thickened with lithium and formulated with a mineral base oil; $\mathrm{LiCaE}$ is thickened with lithium and calcium and formulated with an ester base oil; PPAO is thickened with polypropylene, co-thickened with an elastomer and formulated with a polyalphaolefin base oil. These lubricants were selected for being representative of a study with 6 lubricating greases, where there were two greases of each type, i.e., with the same thickener and base oil type [16].

The lubricating greases and their base oils were provided by the manufacturers. The bled oils were obtained using the modified IP 121 standard test method, as described in [17]. The lubricating greases, their base and bled oils' physicochemical properties were measured and are presented in Table 1. The pressure-viscosity coefficient was determined on the basis of a best $R^{2}$ fit between film thickness measurements and predictions using EHL equations. The test conditions and procedures used to obtain these properties are described in the following sections.

\subsection{Aging Process}

Grease aging was performed in two stages: (i) the grease was sheared during one hour using a roll stability tester to simulate the grease churning phase; (ii) then, a layer of $1 \mathrm{~mm}$ of the sheared grease was spread in a steel plate, which was kept rotating during $72 \mathrm{~h}$ at $130{ }^{\circ} \mathrm{C}$ in an oven with forced air convection. The roll stability tester was shown to be the best way to simulate the mechanical work in rolling bearings by Lundberg et al. [18], and the thermal aging of thin layers of lubricating greases was shown to represent the aging of grease-lubricated rolling bearings well [19].

\subsection{Rheology}

The lubricating greases (fresh and aged), their base and bled oils were rheologically characterized with an AR 1000 rheometer from TA Instruments with a rough plate-plate geometry $(2 R=25 \mathrm{~mm}$; $\mathrm{Ra} \approx 20 \mu \mathrm{m})$ at two different temperatures $\left(40\right.$ and $\left.80{ }^{\circ} \mathrm{C}\right)$.

Dynamic viscosity $(\eta)$ and shear stress $(\tau)$ were measured in flow tests with increasing levels of shear rate $\left(10^{-2} \mathrm{~s}^{-1}<\dot{\gamma}<10^{4} \mathrm{~s}^{-1}\right)$ and a gap of $175 \mu \mathrm{m}$. Pre-shear was performed with shear rates from 0.01 to $1 \mathrm{~s}^{-1}$, followed by a resting time of $15 \mathrm{~min}$ before each measurement.

Storage $\left(G^{\prime}\right)$ and loss $\left(G^{\prime \prime}\right)$ moduli were measured in amplitude sweep tests with an oscillatory shear rate $\left(10^{-4} \mathrm{~s}^{-1}<\dot{\gamma}<10^{1} \mathrm{~s}^{-1}\right)$ of increasing amplitude at a constant frequency (1 Hz) and a gap of $250 \mu \mathrm{m}$. Pre-shear was performed between the end of the linear visco-elastic region (LVE) and the cross-over stress $\left(\tau_{c o}\right)$, followed by a resting time of $15 \mathrm{~min}$ before each measurement.

The pre-shear procedure was intended to "reset" the grease's previous history, clearing internal stresses and reducing the handling differences between samples. 
Table 1. Lubricant properties. PP, polyalphaolefin.

\begin{tabular}{|c|c|c|c|}
\hline & LiM1 & LiCaE & PPAO \\
\hline \multicolumn{4}{|c|}{ Grease } \\
\hline Base oil & Mineral & Ester & PAO \\
\hline Thickener & $\mathrm{Li}$ & $\mathrm{Li}+\mathrm{Ca}$ & PP \\
\hline Thickener content (\%) & 11.29 & 20.49 & 15.48 \\
\hline Biodegradable (-) & - & passed & - \\
\hline NLGI Grade (-) & 2 & 2 & 2 \\
\hline Operating temperature $\left({ }^{\circ} \mathrm{C}\right)$ & $-20 /+130$ & $-30 /+120$ & $-35 /+120$ \\
\hline Refract.Index (-) & 1.4965 & 1.4837 & 1.4892 \\
\hline$G_{c r}(\mathrm{~Pa})$ & 500 & 500 & 500 \\
\hline$n(-)$ & 0.5 & 0.6 & 0.7 \\
\hline \multicolumn{4}{|c|}{ Base Oil } \\
\hline$\rho\left(\mathrm{g} / \mathrm{cm}^{3}\right)$ & 0.903 & 0.952 & 0.828 \\
\hline$\eta_{40}\left(\mathrm{~mm}^{2} / \mathrm{s}\right)$ & 211.05 & 89.84 & 42.78 \\
\hline$\eta_{80}\left(\mathrm{~mm}^{2} / \mathrm{s}\right)$ & 34.49 & 25.11 & 12.36 \\
\hline$\alpha_{40}\left(\mathrm{GPa}^{-1}\right)$ & 28.9 & 16.4 & 20 \\
\hline$\alpha_{80}\left(\mathrm{GPa}^{-1}\right)$ & 23.9 & 12,1 & 11.4 \\
\hline Refrac. Index (-) & 1.4956 & 1.4562 & 1.4592 \\
\hline$G_{c r}(\mathrm{~Pa})$ & - & - & - \\
\hline$n(-)$ & 1 & 1 & 1 \\
\hline \multicolumn{4}{|c|}{ Bled oil } \\
\hline$\rho\left(\mathrm{g} / \mathrm{cm}^{3}\right)$ & 0.909 & 0.919 & 0.843 \\
\hline$\eta_{40}\left(\mathrm{~mm}^{2} / \mathrm{s}\right)$ & 192.1 & 95.43 & 528.83 \\
\hline$\eta_{80}\left(\mathrm{~mm}^{2} / \mathrm{s}\right)$ & 28.86 & 24.98 & 151.95 \\
\hline$\alpha_{40}\left(\mathrm{GPa}^{-1}\right)$ & 43.5 & 27.8 & 24.4 \\
\hline$\alpha_{80}\left(\mathrm{GPa}^{-1}\right)$ & 36.8 & 20.3 & 12.8 \\
\hline Refrac. Index (-) & 1.4948 & 1.4744 & 1.4639 \\
\hline$G_{c r_{40}}(\mathrm{~Pa})$ & - & - & 569.6 \\
\hline$n_{40}(-)$ & 1 & 1 & 0.752 \\
\hline \multicolumn{4}{|c|}{ Additives $\left(w t \% \times 10^{-3}\right)$} \\
\hline Phosphorus (P) & 120 & 37 & 6 \\
\hline Sulfur (S) & 1649 & 102 & 581 \\
\hline Calcium $(\mathrm{Ca})$ & 3 & 3145 & 22 \\
\hline Zinc (Zn) & 285 & 29 & 0 \\
\hline Lead $(\mathrm{Pb})$ & 8 & 0 & 14 \\
\hline Bismuth (Bi) & 0 & 0 & 717 \\
\hline Iron $(\mathrm{Fe})$ & 4.9 & 2.8 & 2.9 \\
\hline
\end{tabular}




\subsection{X-Ray Fluorescence}

The chemical content of fresh and aged greases was analysed with X-ray fluorescence (XRF). It reveals the relation between the intensity of an element to its concentration in the sample, providing a fast way to track chemical changes due to degradation and basic element analysis. The used Spectro Xepos XRF provides, as the output, a list of some chemical elements, from sodium $(Z=11)$ to uranium $(Z=92)$, and their concentration as a percentage of total mass (wt $\%)$. Two samples of each grease were measured.

\subsection{Infra-Red Spectroscopy}

Fourier transform infra-red spectroscopy (FTIR) was applied to the fresh and aged lubricating grease and to its components (base oil, bled oil and thickener) in order to: (i) obtain the spectra of grease, base oil, thickener and bled oil in order to determine the peaks related to the thickener and to the oil in the grease spectrum, as well as to compare the chemical properties of the base and bled oils; and (ii) to evaluate grease changes after severe working conditions by comparing the fresh and aged grease spectra. A Spectra-Tech Nicolet Continuum Infrared Microscope connected to a Nicolet Nexus 670 FTIR spectrometer was used for these characterizations. Background spectra were taken from $\mathrm{NaCl}$ windows. All spectra were collected using 64 scans at a $2 \mathrm{~cm}^{-1}$ resolution at room temperature. All spectra were normalized to the $\mathrm{CH}_{2}$ peak at approximately $1460 \mathrm{~cm}^{-1}$ to prevent disparities between spectra due to different sample thicknesses. To ensure that the results found with FTIR spectroscopy were representative of the composition, each spectrum was taken at least twice.

\subsection{Oil Loss Evaluation}

The thickener/oil ratio of fresh and aged greases was evaluated according to the non-standard test method described in [1].

The method consists of dissolving a certain amount of grease with a solvent (petroleum ether (PE), $40-60{ }^{\circ} \mathrm{C}$ ) and forcing the dissolved grease through a filter with a $0.45 \mu \mathrm{m}$ grid. The oil and the solvent flow through the filter to a container whilst the thickener remains in the filter. The container with the mixture of oil and solvent is submitted to a low vacuum, low rotational speed and temperature of $60{ }^{\circ} \mathrm{C}$ to evaporate the solvent. The solvent remaining in the filter is also evaporated by subjecting it to temperatures of $60^{\circ} \mathrm{C}$. Both oil and thickener are then weighed. The percentage of each component is calculated by comparing the mass of the grease sample before separation to its components after separation. Comparing the thickener and oil mass of fresh and aged greases, it is possible then to determine the oil loss due to the aging process.

\subsection{Film Thickness Measurements}

Lubricant film thickness was measured in a WAM-11A (Wedeven Associates Machine) ball-on-disc test apparatus equipped with optical interferometry. The spacer layer imaging method was used [20], so that lubricant films with a resolution of $1 \mathrm{~nm}$ in the range of 1-700 $\mathrm{nm}$ could be measured. 
The measurements were performed under fully-flooded and starved lubrication with degraded and fresh greases, their base oils and bled oils. All of the tests were performed three times under a pure rolling condition, a constant pressure of $0.5 \mathrm{GPa}$, an entrainment speed varying stepwise ascending and then descending at constant temperatures of $\approx 40,60$ and $80{ }^{\circ} \mathrm{C}$. The minimum and maximum speeds were determined as a function of the film thickness values. The method used here is the lab-method described by Hartl et al. [21]. The tests were divided into 3 parts:

- Fully flooded and moderate to high speeds: performed with the fresh greases, their base oils and bled oils at 40,60 and $80{ }^{\circ} \mathrm{C}$, but also with the aged greases at $40{ }^{\circ} \mathrm{C}$;

- Fully flooded and very low speeds: performed with fresh and aged greases at $40{ }^{\circ} \mathrm{C}$;

- Starved lubrication at constant speed: performed with fresh and aged greases at $40^{\circ} \mathrm{C}$;

The fully-flooded conditions were ensured using a scraper, which re-distributed the grease back to the rolling track. A homogeneous temperature was ensured by three thermocouples strategically positioned on the ball, disc and lubricant during the tests. The largest measured temperature deviation from the target was $\pm 1.5^{\circ} \mathrm{C}$ during the $80{ }^{\circ} \mathrm{C}$ tests. Starved tests were performed, such as the fully-flooded ones, but without using a scraper.

The ball and disc properties are presented in Table 2.

Table 2. Ball and disc data.

\begin{tabular}{lcc}
\hline & Ball & Disc \\
\hline Material & AISI 52100 & glass \\
Elastic modulus $-E(\mathrm{Gpa})$ & 210 & 64 \\
Poisson coefficient $-\nu(/)$ & 0.29 & 0.2 \\
Surface roughness $-R a(\mathrm{~nm})$ & 50 & $\approx 5$ \\
Space layer thickness $-(\mathrm{nm})$ & - & $\approx 160$ \\
Space layer refrac. index $-(/)$ & - & $\approx 1.4785$ \\
\hline
\end{tabular}

\section{Results and Discussion}

\subsection{FTIR}

Infra-red spectroscopy analysis of the fresh samples (grease, thickener, base and bled oils) showed the peaks on the grease spectrum that belong to the thickener, to the base oil and to the additives. It also showed that most of the additives (if not all) remained in the oil during the bleeding process. The additives identified in the bled oil spectra were absent in the base oil spectra, as expected. A few absorbance peaks that might be related to the thickener were observed in the bled oils spectra, as well. Figure 1 shows the (a) grease, (b) bled oil, (c) thickener and (d) a comparison between PPAO base and bled oil spectra as an example. Note that the sinusoidal shape at the base line of Figure 1(c) is due to internal equipment noise and does not represent the thickener characteristics. The infra-red response of LiM1 and LiCaE are given ahead when fresh and aged lubricants are compared. 
The main observation from the FTIR analysis of the fresh samples are given below.

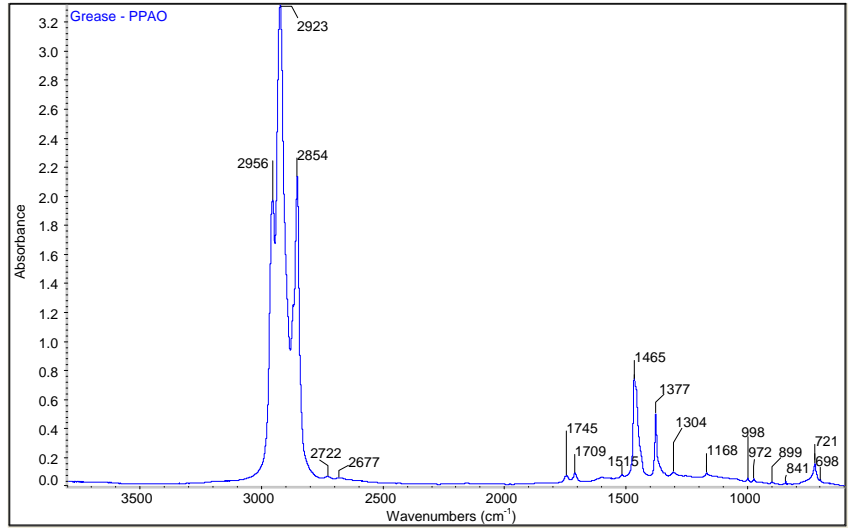

(a)

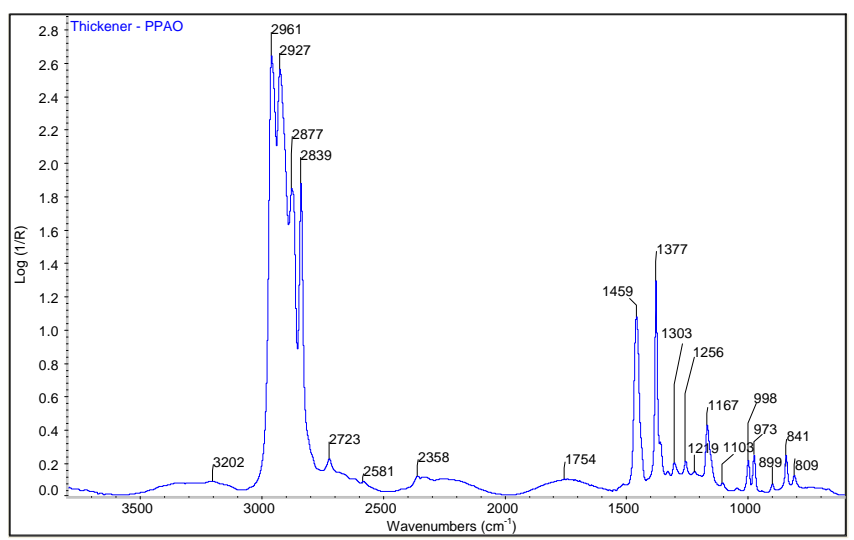

(c)

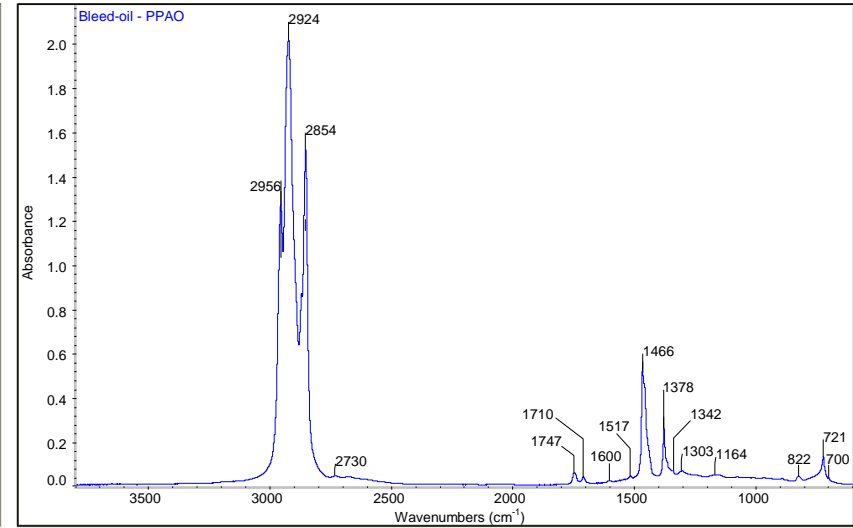

(b)

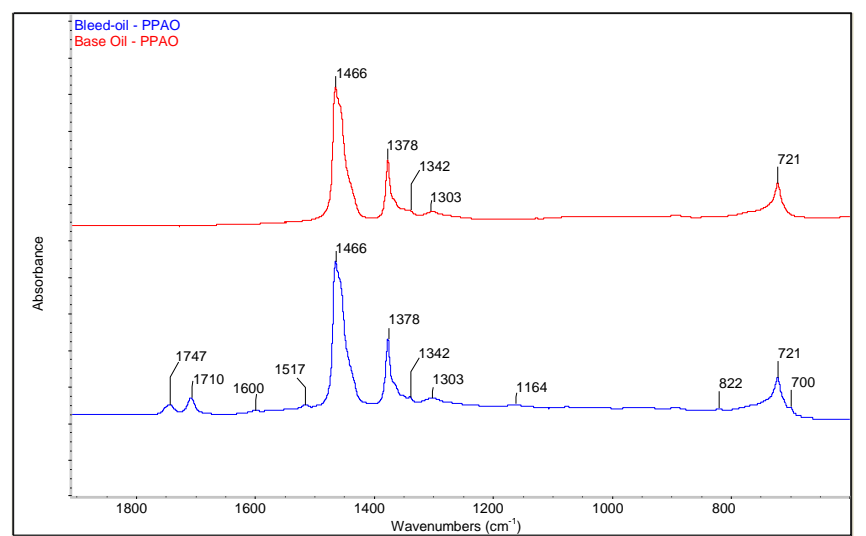

(d)

Figure 1. FTIR spectra of PPAO. (a) Grease; (b) bled oil; (c) thickener; (d) comparison between base and bled oil spectra in the fingerprint zone.

- The broad peak at $3340-3330 \mathrm{~cm}^{-1}$ was seen in the grease and thickener spectra of LiM1 and $\mathrm{LiCaE}$, but absent in the bled oils, indicating that it belongs to the lithium thickener formulation;

- The bands at 1580 and $1560 \mathrm{~cm}^{-1}$ stem from the soap thickener and are assigned as $\mathrm{COO}^{-}$. This is confirmed by their absence in the bleed-oil spectrum [19];

- The band centered at $\approx 1430 \mathrm{~cm}^{-1}$ and the bands at $\approx 1795,874$ and $712 \mathrm{~cm}^{-1}$ were observed in the $\mathrm{LiCaE}$ grease and thickener spectra, but absent in the bled oil, indicating that it belongs to the calcium thickener [22];

- The presence of isotactic polypropylene (iPP) in the PPAO grease and thickener spectra, which were mostly seen at $\approx 998,973,900,841$ and $808 \mathrm{~cm}^{-1}$ [23], were absent in the bled oil spectrum;

- The $\mathrm{CH}_{2}$ and $\mathrm{CH}_{3}$ groups of the base oils are primarily responsible for the peaks at $\approx 2953,2923$, $2850,1460,1377$ and $721 \mathrm{~cm}^{-1}$ in the grease spectrum. Furthermore, the hydrocarbon structure of the thickener contributes to these absorptions [24,25];

- The bands at $\approx 1744,1238$ and $1158 \mathrm{~cm}^{-1}$ were observed in the grease and bled oil spectra of LiCaE, but absent in its thickener spectrum, indicating that it belongs to the ester oil [26]; 
- Peaks with a low intensity of absorbance at $\approx 1600$ and $1516 \mathrm{~cm}^{-1}$ were observed in all grease and bled oil spectra, but absent in the base oils. These peaks are usually attributed to the phenolic and amine antioxidant additives [27,28].

- Several other peaks, usually attributed to the additives, were observed in the PPAO bled oil spectra, such as: (i) $\approx 1747 \mathrm{~cm}^{-1}$, AW additives [29]; (ii) $1710 \mathrm{~cm}^{-1}$, EP/AW additives (bismuth), which is known to be part of the grease formulation (see Table 1); (iii) $\approx 1004 \mathrm{~cm}^{-1}$, AW additives, attributed to ZDDP [30,31]; (iv) a small hump on the $722 \mathrm{~cm}^{-1}$ peak around $700 \mathrm{~cm}^{-1}$, which is due to the co-thickener (rubber) according to the grease manufacturer; $(\mathrm{v}) \approx 1162 \mathrm{~cm}^{-1}$, the viscosity improver [27], which was observed in the LiM1 bled oil spectra, as well.

Figure 2 shows the infra-red spectra of aged and fresh samples of the lubricating greases and their bled oils. Significant changes were observed after aging. It was ascertained that LiM1 grease and its bled oil were not or only slightly oxidized (absence of peaks at the $1750-1700 \mathrm{~cm}^{-1}$ range), but additive consumption (reduction of the peaks at 1600, 1516, 1164 and $1004 \mathrm{~cm}^{-1}$ ) and base oil evaporation were observed (increase of the lithium peaks: 1580 and $1560 \mathrm{~cm}^{-1}$ ). A slightly increase of the $1740-\mathrm{cm}^{-1}$ band caused by oxidation products in the bled oil spectrum was also observed.

LiCaE grease showed moderate to high levels of oxidation by the increase of the base line at the 3700-3000 and 1900-800- $\mathrm{cm}^{-1}$ range, the broadening of the 1740 and $1460 \mathrm{~cm}^{-1}$ bands and the increase in intensity of absorbance of the 1239 and $1165 \mathrm{~cm}^{-1}$ ester peaks [32]. The IR spectra also showed changes in thickener concentration by the relative decrease in intensity of the lithium peak at $1580 \mathrm{~cm}^{-1}$ and the increase of the calcium peak at $872 \mathrm{~cm}^{-1}$ with the normalized one at approximately $1460 \mathrm{~cm}^{-1}$. The aged LiCaE bled oil spectra showed an increasing height of the 3467,1417 and $1240 \mathrm{~cm}^{-1}$ bands and the broadening of the peak at $1740 \mathrm{~cm}^{-1}$, indicating that it is oxidized. Additive depletion was observed by the reduction of the peaks at 1602 and $1517 \mathrm{~cm}^{-1}$.

In the PPAO spectra, it was noticeable that no or just slight oxidation occurred. However, the consumption of AW additives at $1745 \mathrm{~cm}^{-1}$ and the depletion of the extreme pressure and anti-wear additive at $1709 \mathrm{~cm}^{-1}$ (bismuth) are clear. Furthermore, a significant decrease in intensity of the peaks in the region of $2853-2953 \mathrm{~cm}^{-1}$ suggests that the C-H and C-C long chains of PP and/or PAO were broken [33].

\subsection{XRF and Remaining Oil Percentage Analysis}

Table 3 shows the most common elements used on grease additivation and their concentration as a function of the total mass $\left(\mathrm{wt} \% \times 10^{3}\right)$ after the aging process. The relative decrease/increase in percentage of each element after the aging process is also given in the table by $\Delta_{c}=($ Fresh Aged) $/$ Fresh $\times 100$.

The decreased content of some common elements usually used as additives ( $\mathrm{P}, \mathrm{S}, \mathrm{Ca}, \mathrm{Zn}, \mathrm{Pb}, \mathrm{Bi}$ ) was observed by comparing the XRF data of fresh and aged grease samples. This supports the FTIR analysis presented in the previous section. Table 3 also shows an increase of the iron content (Fe) in the LiM1 (28.2\%) and LiCaE (535.7\%) greases, which could be related to the grease's ability to protect the contacting surfaces, either by forming a hydrodynamic film or a boundary film (thickener and/or additives). As shown by Hurley et al. [19], oxidation occurs more rapidly and reaches higher levels in 
the presence of metallic debris. Therefore, the high content of Fe together with the low additization of the LiCaE grease are likely to be the main reason for its high level of oxidation.

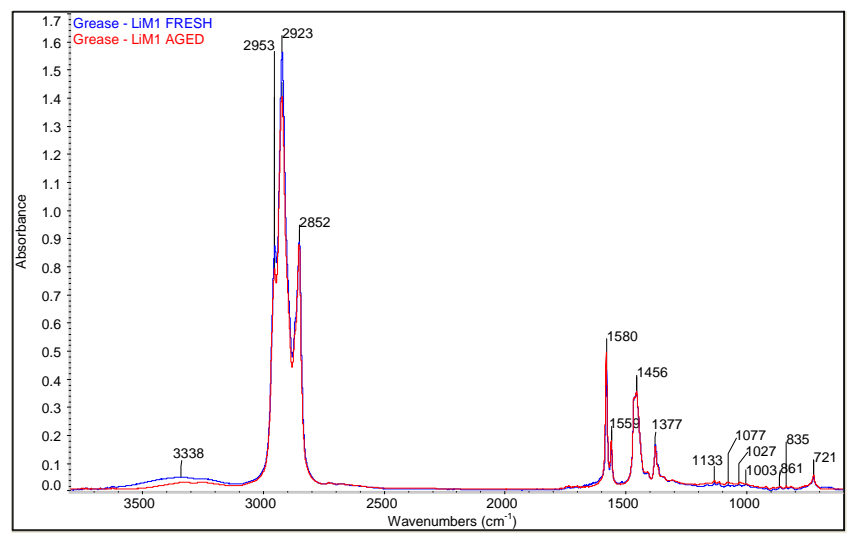

(a)

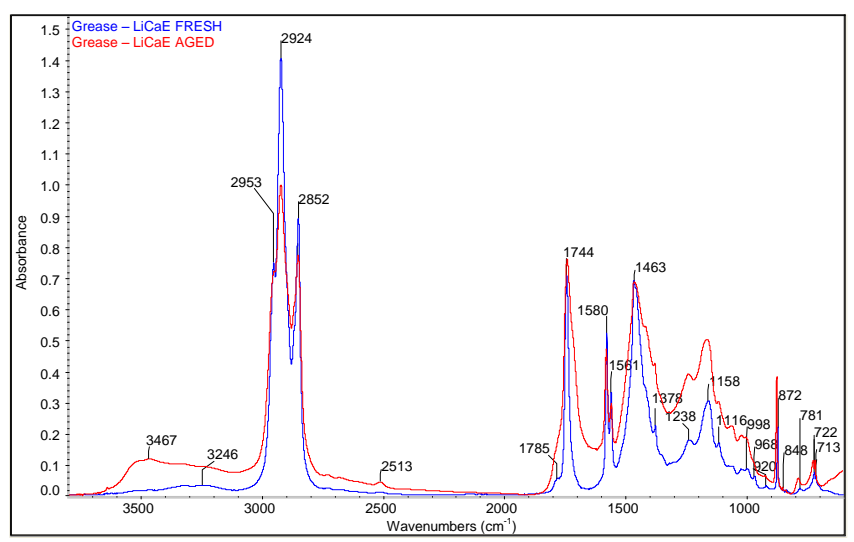

(c)

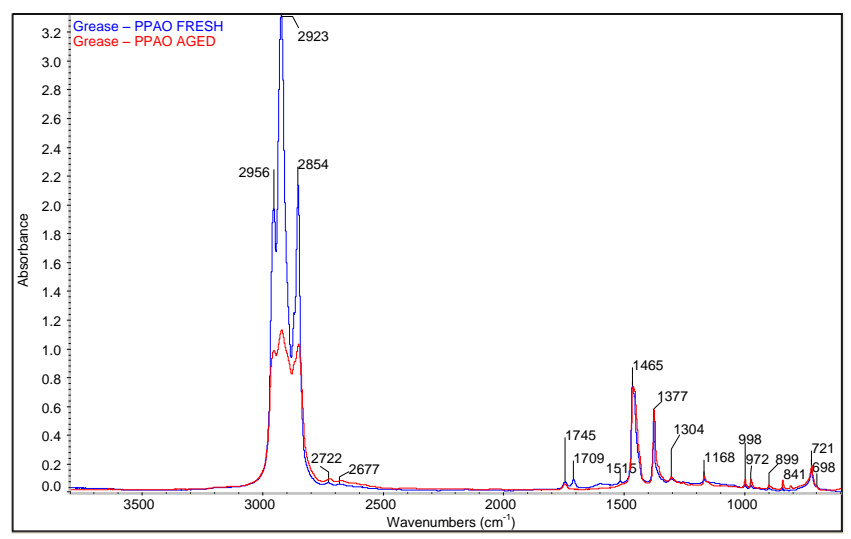

(e)

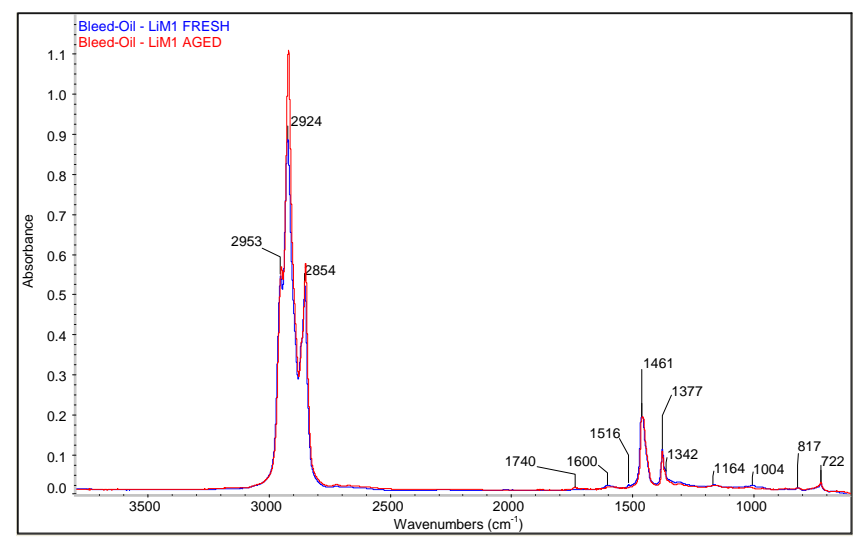

(b)

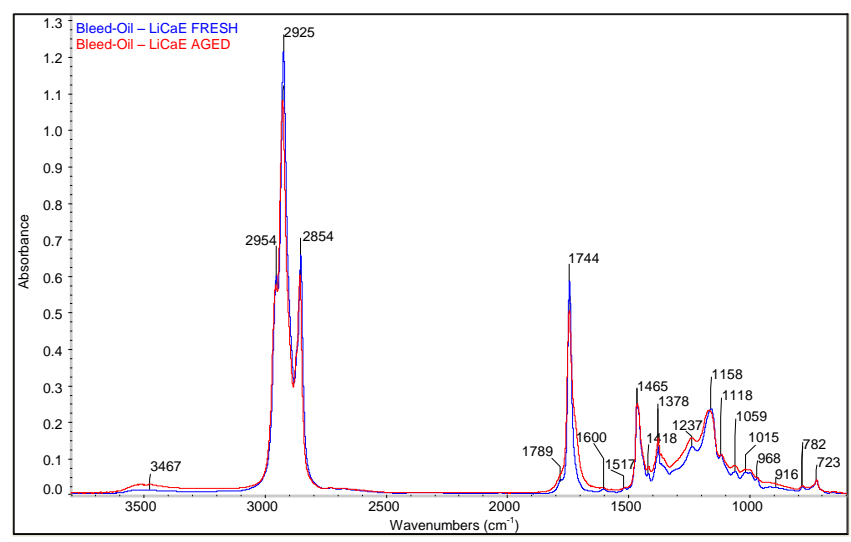

(d)

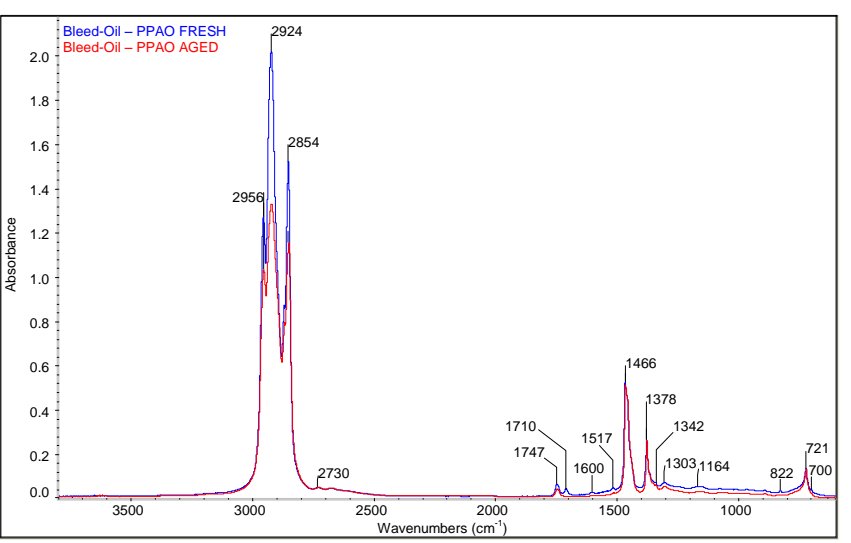

(f)

Figure 2. FTIR spectra of fresh and aged samples. (a) LiM1 grease; (b) LiM1 bled oil; (c) LiCaE grease; (d) LiCaE bled oil; (e) PPAO grease; and (f) PPAO bled oil. 
Table 3. Concentration in percentage of total mass $\left(\mathrm{wt} \% \times 10^{-3}\right)$ of the chemical content of aged grease samples and their $\Delta_{c}$.

\begin{tabular}{llllllll}
\hline & $\mathbf{P}$ & $\mathbf{S}$ & $\mathbf{C a}$ & $\mathbf{Z n}$ & $\mathbf{P b}$ & $\mathbf{B i}$ & $\mathbf{F e}$ \\
\hline Aged LiM1 & 82.5 & 696.5 & 3.0 & 156.4 & 8.0 & 0.0 & 6.3 \\
$\Delta_{c}$ & 31.3 & 57.8 & 0.0 & 45.1 & 0.0 & 0.0 & -28.2 \\
\hline Aged LiCaE & 23.5 & 63.4 & 1958.0 & 12.3 & 0.0 & 0.0 & 17.8 \\
$\Delta_{c}$ & 36.6 & 37.8 & 37.7 & 57.6 & 0.0 & 0.0 & -535.7 \\
\hline Aged PPAO & 2.2 & 123.4 & 0.2 & 0.0 & 11.4 & 643.6 & 2.9 \\
$\Delta_{c}$ & 64.2 & 78.8 & 99.0 & 0.0 & 18.8 & 10.2 & 0.0 \\
\hline
\end{tabular}

\subsection{Viscosity Evaluation and Oil Loss}

Figure 3 shows the measured dynamic viscosity of the fresh and aged base and bled oils versus the shear rate $(\eta \times \dot{\gamma})$ at $40{ }^{\circ} \mathrm{C}$.

Fresh and aged base and bled oils of LiM1 and LiCaE presented a Newtonian behavior, while the fresh and aged bled oils of PPAO showed a significant shear thinning behavior. Besides, base and bled oil viscosities were shown to be quite different. Table 4 shows these differences in the low shear rate range, where:

$$
\begin{aligned}
\Delta \eta_{\text {fresh }} & =\left(\eta_{\text {Basefresh }}-\eta_{\text {Bledfresh }}\right) / \eta_{\text {Basefresh }} \times 100 \\
\Delta \eta_{\text {aged }} & =\left(\eta_{\text {Bledfresh }}-\eta_{\text {Bledaged }}\right) / \eta_{\text {Bledfresh }} \times 100
\end{aligned}
$$

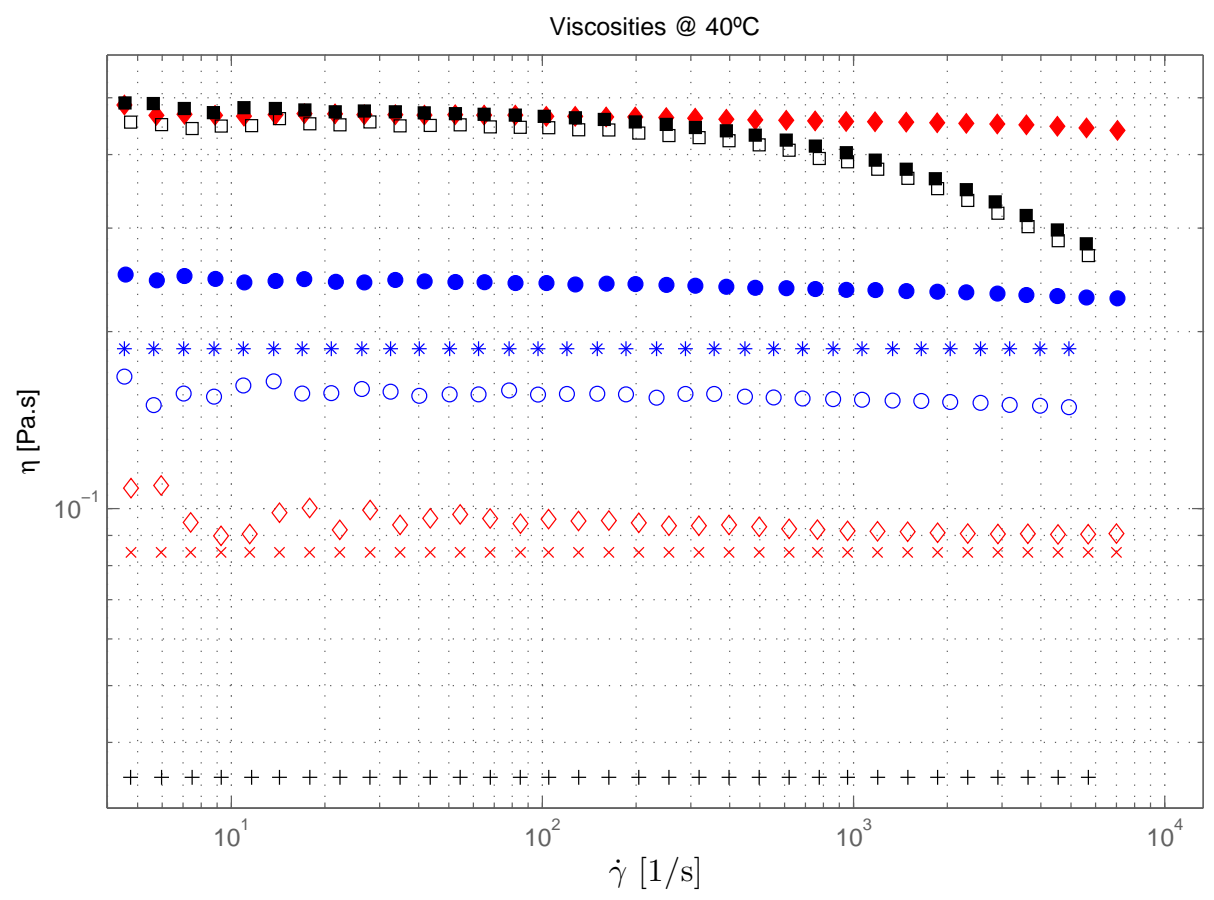

Figure 3. Flow curves at $40{ }^{\circ} \mathrm{C}$. LiM1 base oil (*), LiM1 bled oil (o), LiM1 aged bled oil $(\bullet)$, LiCaE base oil $(\times)$, LiCaE bled oil $(\diamond)$, LiCaE aged bled oil $(\diamond)$, PPAO base oil $(+)$, PPAO bled oil ( $\square$ ) and PPAO aged bled oil (ם). 
Three different trends were observed when fresh base and bled oil viscosities were compared at $40{ }^{\circ} \mathrm{C}$. LiCaE grease presented similar values for base and bled oil viscosities. In the case of LiM1 grease, the viscosity of the bled oil was $17 \%$ lower than the viscosity of the base oil, while in the case of PPAO grease, the viscosity of the bled oil was $1150 \%$ higher than the one of the base oil.

Table 4. Base and bled oils viscosity difference in the low shear rate range at $40{ }^{\circ} \mathrm{C}$.

\begin{tabular}{lccl}
\hline & LiM1 & LiCaE & PPAO \\
\hline$\Delta \eta_{\text {fresh }}(\%)$ & -17 & 12 & 1150 \\
$\Delta \eta_{\text {aged }}(\%)$ & 54 & 382 & 6.8 \\
\hline
\end{tabular}

The IR-spectra had already shown different compositions between base and bled oils, and therefore, distinct physical and rheological properties were already expected. According to the manufacturer of the PPAO grease, the very high viscosity of its bled oil is mainly due to the co-thickener, which has a large affinity with the base oil and always bleeds out together during the bleeding process. The co-thickener was found in the bled oil IR spectrum (Figure 2(e)).

Aged bled oils showed the same viscosity behavior of their corresponding fresh bled oils, but at higher levels, as shown in Table 4 and Figure 3.

Figure 4 shows that $\Delta \eta_{\text {aged }}$ increases in a power law fashion with increasing oil loss $\left(\Delta_{\text {oil }}\right)$. Grease oil loss most likely occurs due to evaporation and/or bleeding that occurred during the aging process; and the increase in viscosity can be related to different reactions that occur during the aging process, such as evaporation of the low weight compounds of the base oil and formation of high molecular weight molecules (polymerization). Due to the low level of oxidation observed in the LiM1 and PPAO lubricants, the increase in viscosity is probably due to the evaporation of the low weight compounds of the base oil, while the significant increase in the bled oil viscosity observed in the case of LiCaE is also attributed to polymerization, since LiCaE is highly oxidized.

Thermo-gravimetric analysis should be performed to confirm the results.

\subsection{Rheological Analysis of the Lubricating Greases}

The flow curves of fresh and aged lubricating greases and their bled oils are shown in Figure 5. The theoretical values were calculated using the Cross model (re-written in terms of shear stress) for pseudo-plastic flow (see Equation (1)) [34]. This model describes the variation of the shear stress for the full shear rate range with reasonable accuracy and reads:

$$
\tau=\left[\frac{\eta_{0}-\eta_{\infty}}{1+(K \dot{\gamma})^{m}}+\eta_{\infty}\right] \dot{\gamma}
$$

where $\eta_{0}$ is the viscosity at very low shear rates (obtained from the oscillatory tests), $\eta_{\infty}$ is the viscosity at medium to high shear rates (obtained from flow tests) and $K$ and $m$ are model constants, known as the critical stress and the power-law index, respectively. In the present work, $\eta_{\infty}$ is assumed to be equal to the bled oil viscosity, and the model constants $K$ and $m$ were determined from Equation 1 by fitting 
them with the experimental results. The grease viscoelastic parameters obtained from the oscillatory tests are presented in Table 5.

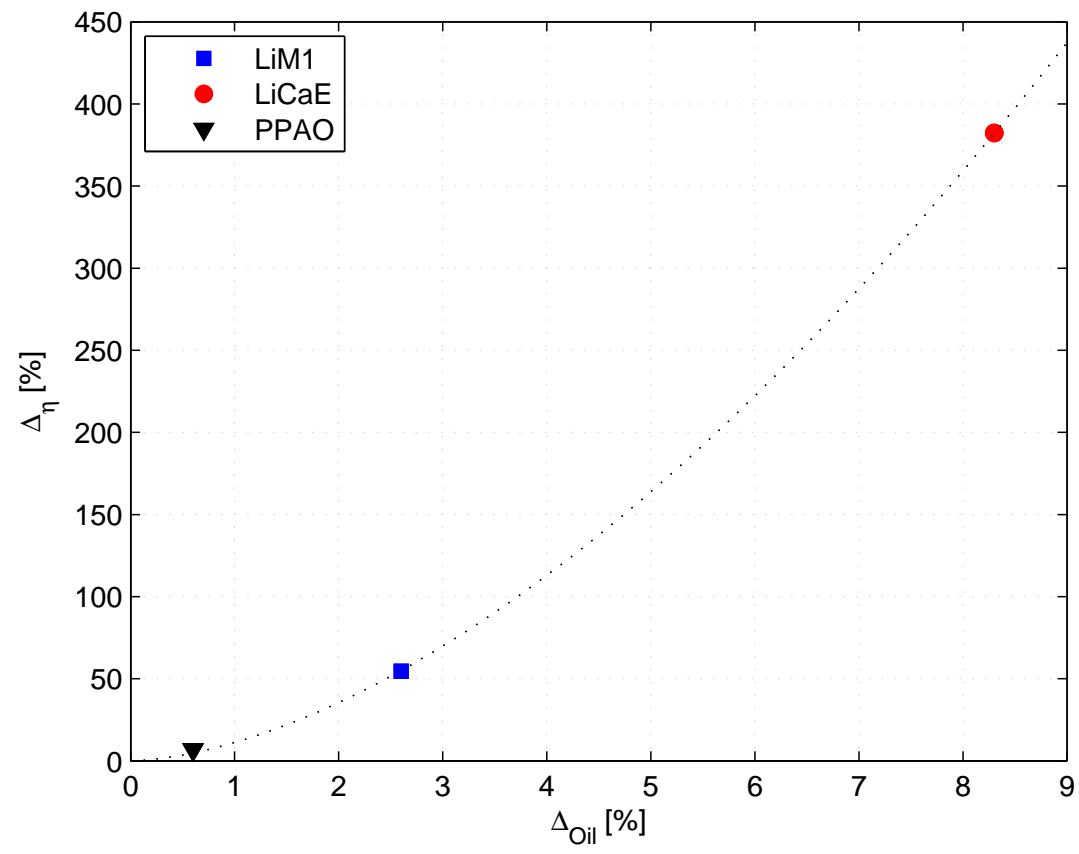

Figure 4. Relative dynamic bled oil viscosity versus oil loss $\left(\Delta \eta \times \Delta_{\text {oil }}\right)$.

Although aged samples of LiM1 are not or just slightly oxidized, additive consumption, oil loss and increased bled oil viscosity were observed. This suggests evaporation of the low weight compounds in the base oil. The oil loss, due to bleeding and evaporation, promotes grease stiffening, which was observed by the increase of all rheological parameters $\left(G^{\prime}, G^{\prime \prime}\right.$ and $\left.\tau \times \dot{\gamma}\right)$.

Aged samples of LiCaE showed significant oxidation, thickener degradation and oil loss. Consequently, a significant increase in bled oil viscosity was observed. At low stresses (low shear rate or low shear stress), where the rheological response of lubricating greases are dominated by their thickener structure, the aged LiCaE sample showed a softening behavior, which is likely due to thickener breakdown (chain-scission reactions) and might be related to the formation of oxidation products. This can be observed by its lower oscillatory parameters $\left(G^{\prime}\right.$ and $\left.G^{\prime \prime}\right)$ and lower shear stress values at the low shear rate range $\left(\dot{\gamma}<10 \mathrm{~s}^{-1}\right)$ in the flow curve (Figure 5). However, at higher stresses (high oscillatory stress and high shear rate), where the rheological response of the lubricating greases are dominated by their oil, the LiCaE aged sample showed a stiffening behavior due to its increased bled oil viscosity. This was verified by its higher oscillatory parameters $\left(G^{\prime}\right.$ and $\left.G^{\prime \prime}\right)$ and higher shear stress values at high shear rates $\dot{\gamma}>10 \mathrm{~s}^{-1}$ in the flow curve.

Aged samples of PPAO were not or just slightly oxidized; the oil loss and viscosity increase were low, but significant chemical changes in the range of 2853-2953 $\mathrm{cm}^{-1}$, representing chain-scission reactions, were observed. Chain scission reactions shorten PP chain length and consequently lead to decreasing values of apparent viscosity and other rheological properties [35], which decreases significantly the grease consistency. This was noted in all rheological parameters $\left(G^{\prime}, G^{\prime \prime}\right.$ and $\left.\tau \times \dot{\gamma}\right)$ that were measured. 


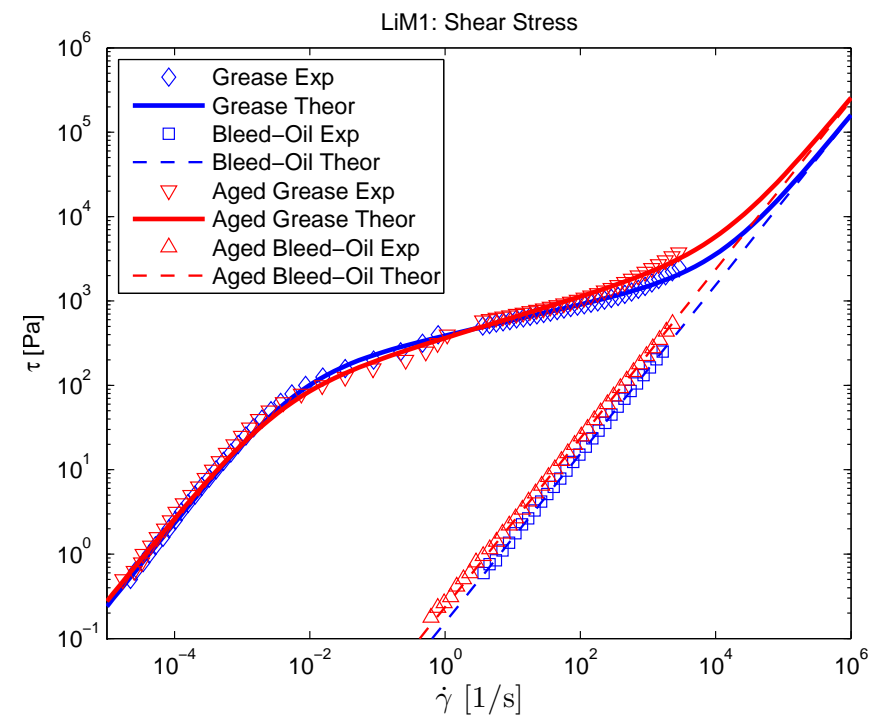

(a)

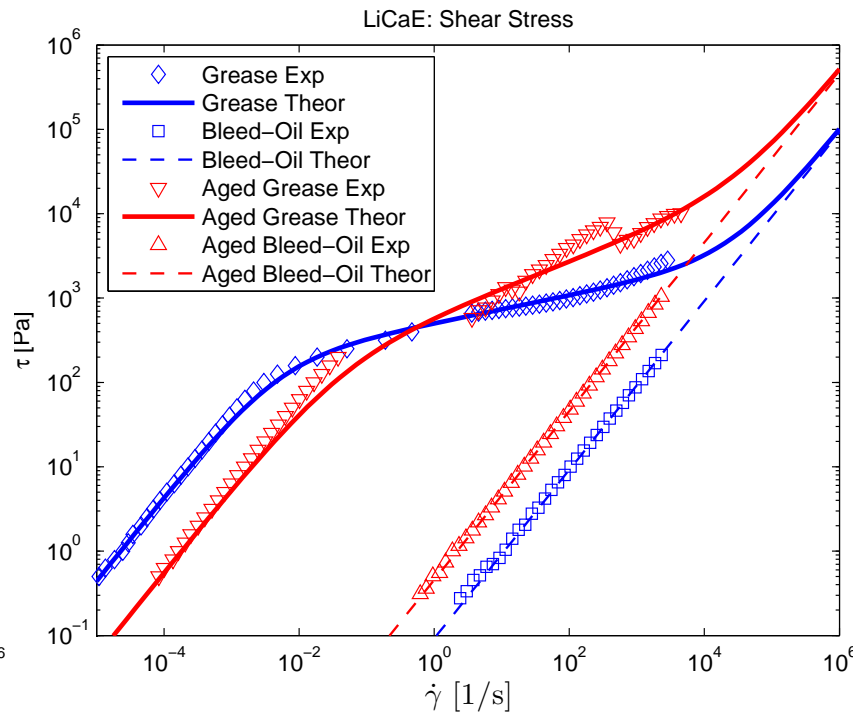

(b)

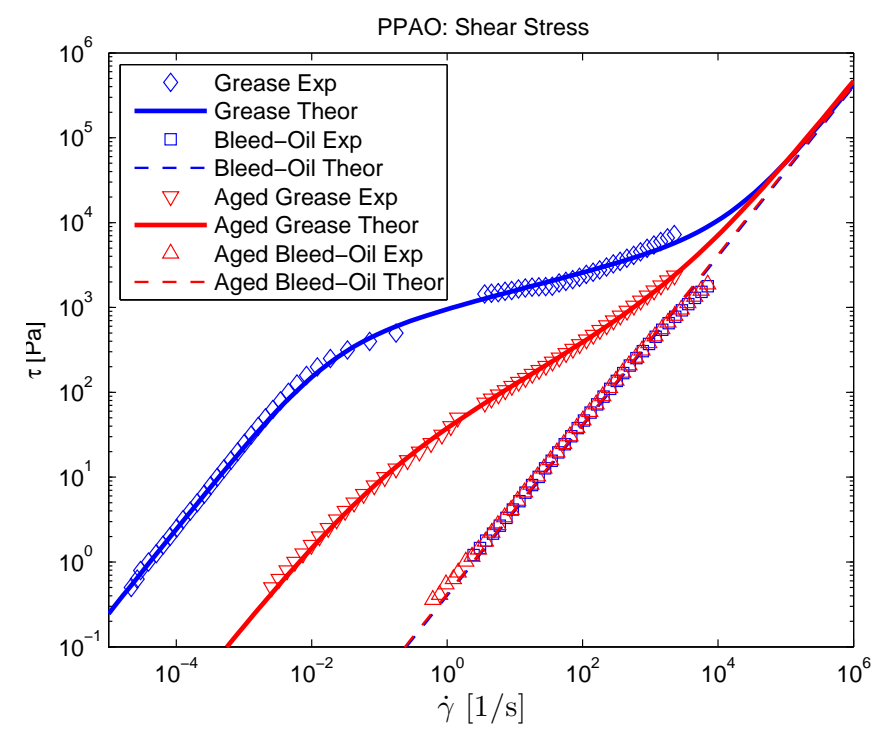

(c)

Figure 5. Shear stress versus shear rate. Comparison between fresh and aged samples. (a) LiM1; (b) LiCaE; and (c) PPAO.

Table 5. Storage and loss moduli versus oscillatory stress. Comparison between fresh and aged samples at $40{ }^{\circ} \mathrm{C}$ in the visco-elastic region (LVE) region.

\begin{tabular}{rrrrr}
\hline Grease & $G_{f}^{\prime}(\mathbf{P a})$ & $G_{a}^{\prime}(\mathbf{P a})$ & $G_{f}^{\prime \prime}(\mathbf{P a})$ & $G_{a}^{\prime \prime}(\mathbf{P a})$ \\
\hline LiM1 & 23,690 & 27,523 & 2,778 & 2,958 \\
LiCaE & 44,893 & 5,847 & 5,895 & 2,740 \\
PPAO & 24,957 & 28 & 4,394 & 56 \\
\hline
\end{tabular}

It is important to notice that the PPAO aged grease viscoelastic response (Figure 5(c) and Table 5) has practically vanished, and its consistency decreased considerably. This has serious implications on grease 
performance, since lubricating greases should be attached to the seals, bearing shoulders or cage, forming a lubricant reservoir and providing a sealing action. Without a proper viscoelastic behavior under low stress level $\left(G^{\prime}>G^{\prime \prime}\right)$, lubricating greases cannot provide an appropriate lubrication, as observed by Lundberg et al. [18,36].

\subsection{Film Thickness: Fully-Flooded}

Figure 6 shows the central film thickness versus the entrainment speed of the fresh lubricating greases, their corresponding base and bled oils at a constant temperature of $\approx 40{ }^{\circ} \mathrm{C}$. The results at 60 and $80{ }^{\circ} \mathrm{C}$ showed the same trends and can be seen in [2].

This figure showed the typical increase of the film thickness with an entrainment speed at a rate of approximately $U^{0.67}$ for all lubricants, suggesting a Newtonian behavior in the inlet region [37]. This figure also shows that the mineral lubricants have the highest film thickness values, followed by the ester ones, which are just slightly higher than the PAO lubricants. It is important to notice that film thickness does not follow the same order of the bled oils low shear viscosity due to the shear thinning characteristics of the PAO bled oil, as detailed in [38]. Furthermore, it is shown that each grease and its bled oil generated a similar central film thickness, which is higher than the ones generated by the base oils.

Other evidence showing that bled oil better characterizes lubricating grease film formation than its base oil was shown by Per-Olof Larsson [39] in 1996 and by Couronné et al. [40] in 2003, both of whom obtained bled oil through static bleed tests.

The recent publication of Morales et al. [3] showed that grease film thickness prediction using the base oil properties might differ significantly from the measured ones depending on the grease type and operating conditions. In a further work, Morales [41] attempted to predict the film thickness of the lubricating greases that behaved different than their base oils using the bled oil properties, which did not work as well. These results are extremely important, because they showed that, for some types of grease, film thickness prediction under fully-flooded lubrication is still a challenge. This brings back the focus of the study of EHL film formation on grease-lubricated contacts, which so far has been considered to be equal to the base oil film thickness. It also opens new research lines to predict grease film formation considering the grease properties under typical EHL conditions instead of film measurements.

The relative film increment between base and bled oils (or greases and their base oils, since $h_{\text {grease }} \approx$ $\left.h_{\text {bledoil }}\right)$ is particular to each lubricant and depends on the operating conditions. At $40{ }^{\circ} \mathrm{C}$, this difference is $\approx 80 \%$ in the case of the PPAO, $40 \%$ in the case of the LiCaE and only $10 \%$ in the case of the LiM1. Such differences were shown to increase significantly with temperature [2].

Cann et al. [6] also studied the difference in central film thickness between greases and their base oils. She observed differences from $2.5 \%$ to $24.8 \%$ for lithium greases formulated with conventionally-refined base stocks and that this difference increased up to $88 \%$ when calcium was blended with the lithium, although thickener concentration, base oil type and viscosity were kept constant.

The lines shown in Figure 6 represent the film thickness prediction of base and bled oils considering the measured temperature, which explains the stepwise shape of these curves. The used methodology to calculate these values considers the shear thinning behavior of the PAO oils and is presented in [38]. 

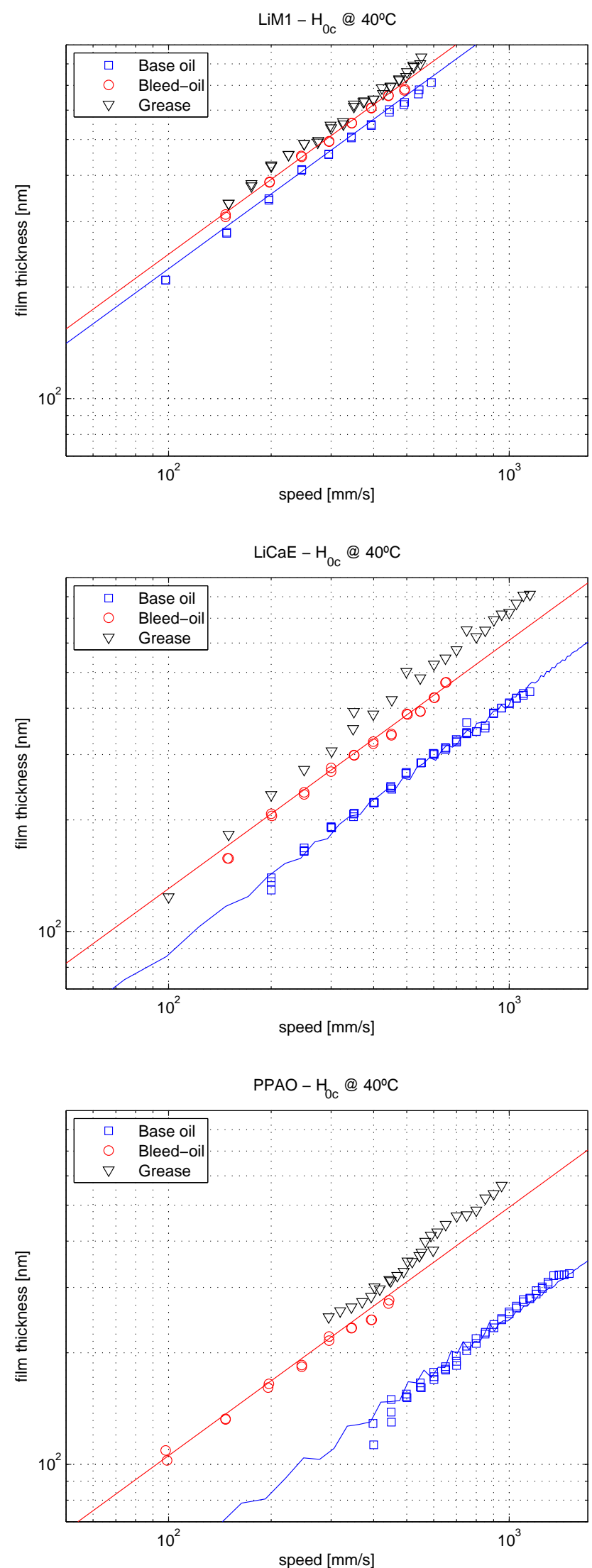

Figure 6. Film thickness versus entrainment speed: comparison between grease, base oil and bled oil at $40{ }^{\circ} \mathrm{C}$. 


\subsection{Film Thickness: Fully Flooded and Low Speeds}

Figure 7 shows the measured (markers) and predicted (continuous lines) film thickness values versus entrainment speed for all lubricating greases and their bled oils.

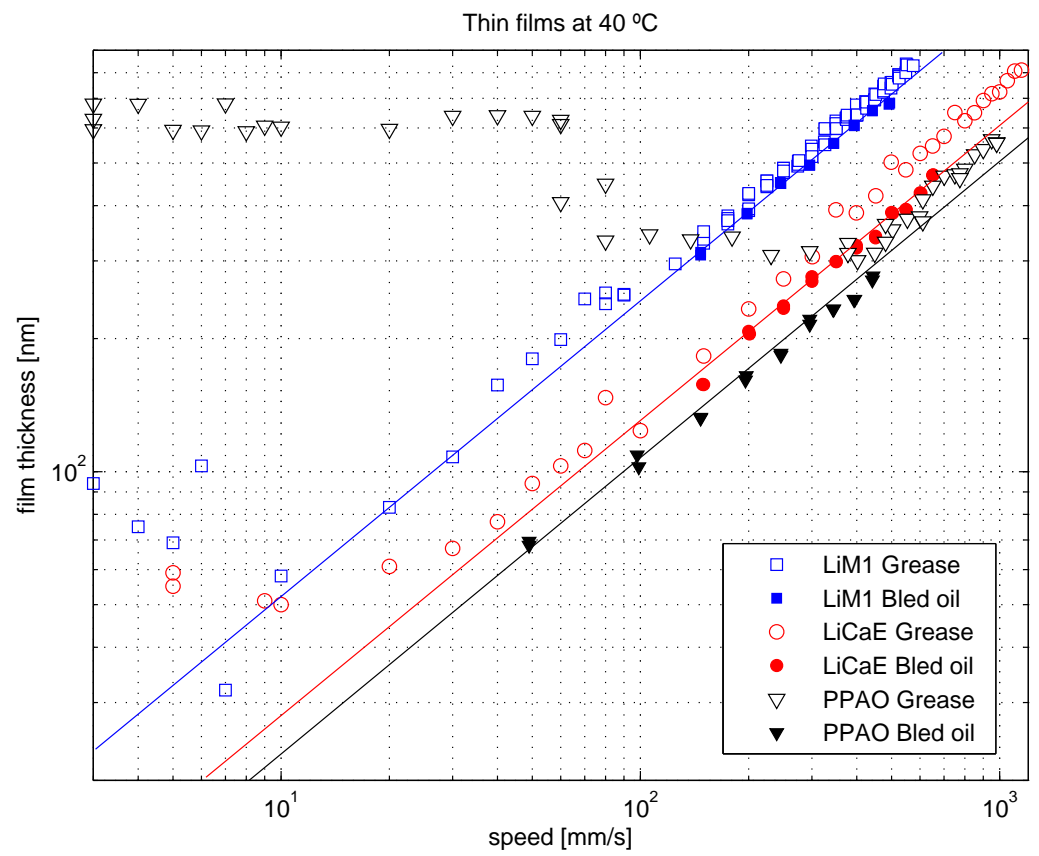

Figure 7. Thin film thickness measurements versus entrainment speed at $40{ }^{\circ} \mathrm{C}$ and $P_{0}=0.5 \mathrm{GPa}$. Greases and bled oils.

The grease film thickness behavior (e.g., $h \propto U^{0.67}$ ) mostly differs from that of its bled oil at low speeds. While the bled oil film thickness decrease rate $\left(h \propto U^{0.67}\right)$ remains constant when the speed goes towards zero, lubricating greases show a decreased rate that goes from $\approx U^{0.67}$ at high speeds, pass by a minimum value $\left(U_{h m i n}\right)$ and increase again up to very high values when the speed goes towards zero. In this last region, measurements fluctuate wildly, the standard deviation is very high and the increasing film thickness with decreasing speeds is not always linear (in a log-log plot).

The speed value with which the film thickness changes its manner $\left(U_{h m i n}\right)$ depends on grease formulation. LiM1 changed the traditional Newtonian behavior when $U_{h m i n} \approx 10 \mathrm{~mm} / \mathrm{s}, \mathrm{LiCaE}$ at $U_{\text {hmin }} \approx 20 \mathrm{~mm} / \mathrm{s}$ and PPAO at $U_{h m i n} \approx 300 \mathrm{~mm} / \mathrm{s}$. At speeds lower than $U_{h m i n}$, lubricating greases showed an increasing trend, with PPAO grease reaching values of $h_{o c} \approx 750 \mathrm{~nm}$.

The PPAO lubricating grease showed a better capacity for forming a thick film at low speeds, followed by the LiCaE and LiM1. This is most likely related to the thickener type, morphology and concentration, since such behavior was not as evident in the bled oils, where several additives, but no or hardly no thickener, were evidenced (see Figure 1). It is also important to notice that whatever contributed to the film formation at low speeds did not contribute (or its contributions are negligible) at higher speeds, where the grease film thickness is similar to the bled oil film thickness. This suggests that the film thickness at low speeds is mostly governed by the thickener, co-thickener and additives passing through the contact instead of chemical absorption. 


\subsection{Film Thickness under Starved Lubrication}

Figure 8 shows the film thickness measurements under starved conditions during $t=30$ min at $40{ }^{\circ} \mathrm{C}$ and $U e=0.1 \mathrm{~m} / \mathrm{s}$. All greases revealed a quick film thickness decay followed by a significant reduction of the decay rate with time (stabilization). Table 6 shows the average film thickness for $t>1250 \mathrm{~s}$.

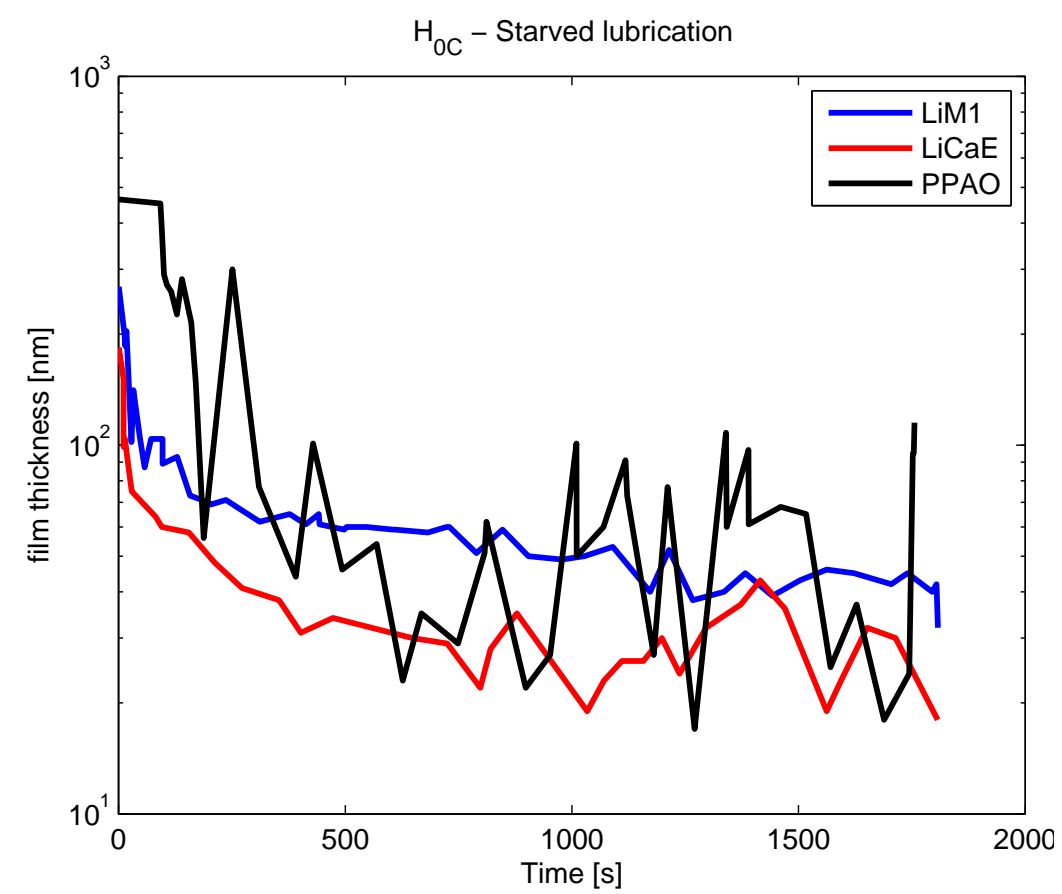

Figure 8. Starved grease film thickness versus time at $P_{0}=0.5 \mathrm{GPa}, T=40{ }^{\circ} \mathrm{C}$ and $U e=100 \mathrm{~mm} / \mathrm{s}$.

Table 6. Average film thickness for $t>1250 \mathrm{~s} . P_{0}=0.5 \mathrm{GPa}, T=40{ }^{\circ} \mathrm{C}, U e=100 \mathrm{~mm} / \mathrm{s}$.

\begin{tabular}{lccc}
\hline & LiM1 & LiCaE & PPAO \\
\hline Film thickness (nm) & 50.4 & 28.3 & 63.2 \\
Variation (nm) & \pm 16 & \pm 12 & \pm 45 \\
\hline
\end{tabular}

The very high standard deviation in these measurements is related to grease materials crossing the contact, as already reported by $[9,37,42]$. This may indicate that the constituents of PPAO grease pass through the contact more often and in larger lumps than the constituents of LiM1 and LiCaE, which is in agreement with the findings of Couronné et al. [40] and Cann et al. [43] and with the thickener size presented in a previous work [17].

Longer test periods and measurements at zero speed should be performed for a better evaluation of a grease's capacity to form a film under starved lubrication. The results shown in Figure 8 only indicate that PP seems to contribute the most to increasing the film locally, Li seems to contribute the least, whilst $\mathrm{Ca}$ is in between the two. This could be related to the thickener's capacity to survive mechanical work to which it is submitted, and thus, the thickener that survives this work with larger lumps is more likely to generate higher local film increasing. 
In case the local increase in film thickness were disregarded after stabilization (time $>1250 \mathrm{~s}$ ), the film thickness would be higher for LiM1 grease $(\approx 40 \mathrm{~nm})$, followed by LiCaE, which is only slightly higher than PPAO (both $\approx 20 \mathrm{~nm}$ ). This suggests that the lubricant film is formed by a thin layer of bled oil and is constantly, but momentarily, increased by the thickener passing through the contact.

\subsection{Film Thickness: Aged and Fresh Greases under Fully-Flooded and Starved Lubrication}

Throughout Sections 3.1 to 3.4, several significant changes to the lubricating greases and their bled oil viscosities due to aging (degradation) were shown. Changes to the pressure-viscosity coefficient, therefore, are also expected, as verified by Bair et al. [44]. Consequently, the capability of aged greases to form and keep a separating film might be different from fresh greases.

These differences are shown in Figure 9, where the film thickness measurements under fully-flooded (left) and starved (right) conditions are presented for the fresh and aged grease samples.

All of the aged greases generated higher film thickness values than the fresh ones. Some of those were above the measuring limit $(\approx 750 \mathrm{~nm})$ of the optical device. This is depicted by the constant film thickness values of $\approx 750 \mathrm{~nm}$ observed in the figures.

In the case of aged LiM1 grease, oil loss and low levels of oxidation and of rheological changes, together with the significant increase in bled oil viscosity $\Delta_{\eta} \approx 54.6 \%$, suggest that the grease lubrication mechanisms are still similar to the fresh one, although the bled oil is more viscous. Therefore, this increase in viscosity might explain the increased film thickness of $\Delta_{h} \approx 40 \%$.

Under starved conditions, fresh and aged LiM1 samples showed similar film thickness decay with time. According to the thin layer flow model developed by Venner, et al. [45], lubricating greases with higher oil viscosity at the contact inlet should present a lower decay rate with time. This was not observed here, which may indicate that the other constituents of the grease play a role in the film decay rate.

$\mathrm{LiCaE}$ grease showed much higher film thickness values after the aging process. Even at a low speed $(100 \mathrm{~mm} / \mathrm{s})$, the measured film thickness values were above the limit of the optical device $(\approx 750 \mathrm{~nm})$. Contrary to the LiM1, aged LiCaE was highly oxidized, lost a significant amount of oil, presented several rheological changes, additive consumption and an increase in bled oil viscosity of $\Delta_{\eta} \approx 382 \%$. Furthermore, when submitted to the centrifugal oil bleed test (ASTM D4425), it did not release any oil during $72 \mathrm{~h}$ running at high speeds $(2000 \mathrm{rpm}$; that is, $\approx 20 \mathrm{~m} / \mathrm{s})$ and at $70{ }^{\circ} \mathrm{C}$. This suggests that the lubrication mechanisms of the aged $\mathrm{LiCaE}$ grease are not solely governed by its more viscous oil (which would not justify by itself the film thickness increasing), but also by a material with enhanced viscosity or a solid-like thick film, which may be formed by oxidation products and/or thickener material and/or bled oil.

Under starved lubrication, the aged sample of $\mathrm{LiCaE}$ retained a significantly high film thickness over time, while the fresh sample decayed rapidly. The film thickness values of the aged sample are approximately one hundred-times higher than the fresh one when $t=30 \mathrm{~min}$. The almost time-independent film thickness of the aged grease supports the idea of the active film having an enhanced viscosity that is not easily ejected by pressure or centrifugal forces or being a deposited solid-like layer. 


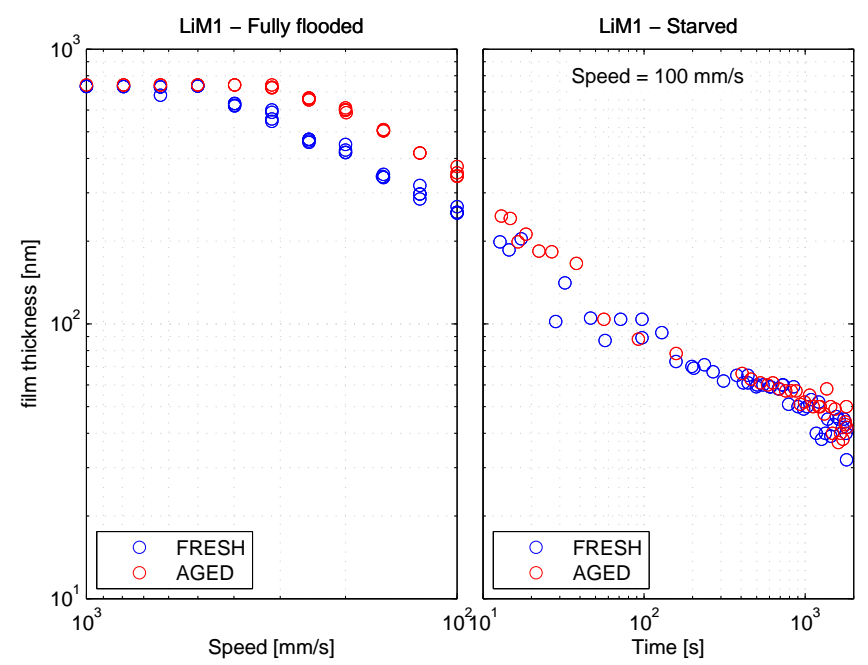

(a)

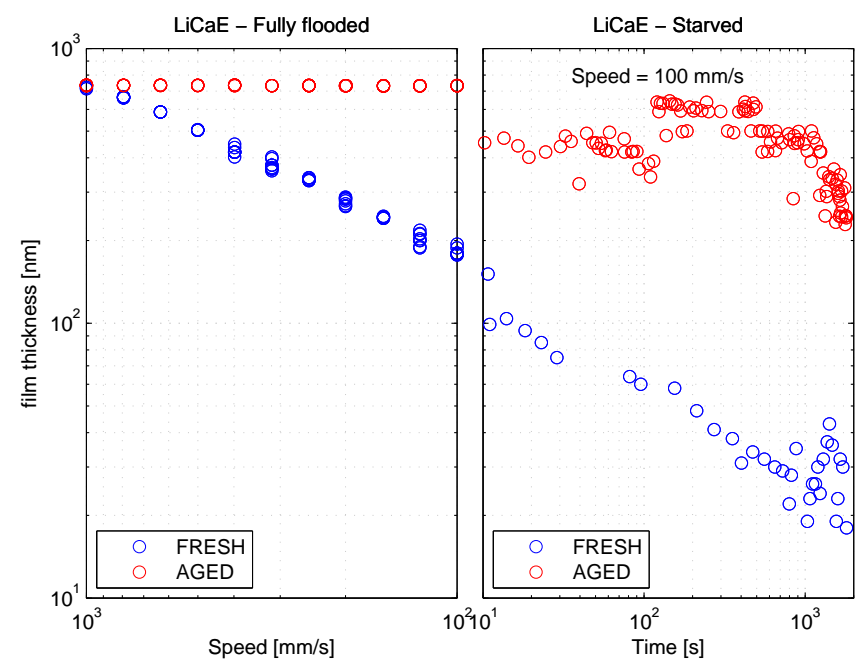

(b)

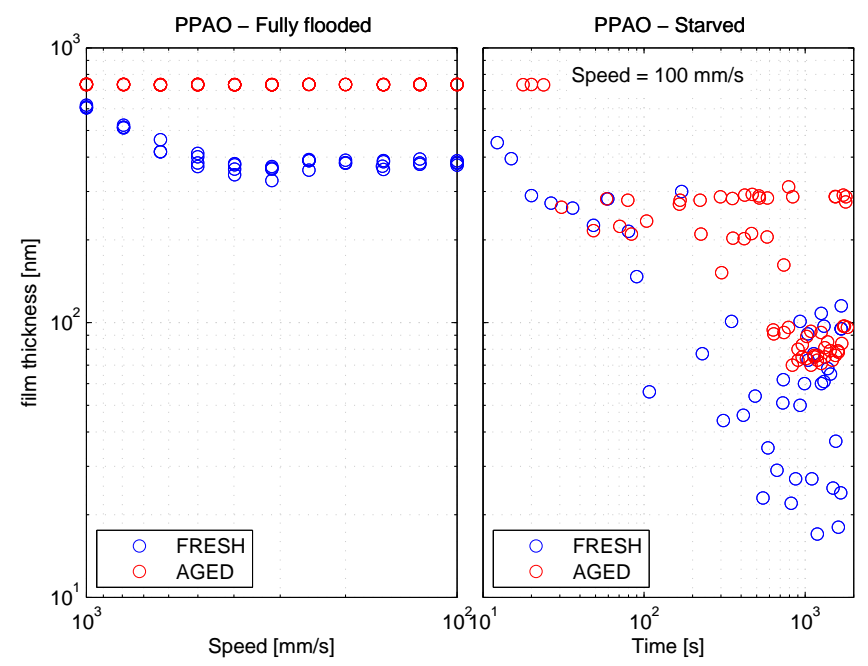

(c)

Figure 9. Film thickness versus entrainment speed. Comparison between fresh and aged samples (a) LiM1, (b) LiCaE and (c) PPAO. 
In fact, Cann [46] showed that the presence of additives seems to prevent thickener deposition and that non-additized greases generated deposited films consisting mostly of degraded thickener as high as $600 \mathrm{~nm}$ (after $300 \mathrm{~min}$ ), while additized greases did not form such thick films. In the case of LiCaE, where most of additives were consumed after aging, it is likely that the film is not solely controlled by the bled oil properties, but also by a solid-like or enhanced viscous film formed mostly of degraded grease with a high thickener content deposited in the track.

Under fully-flooded lubrication, PPAO also showed higher film thickness values after the aging process. At a speed of $300 \mathrm{~mm} / \mathrm{s}\left(U_{h m i n}\right)$, the relative film thickness increment is at least $110 \%$. This film thickness increment is not clear. This does not seem to be related to the bled oil properties, because the increasing in viscosity with aging was small $\Delta \eta \approx 6.8 \%$, which most likely implies small changes of the pressure-viscosity coefficient, $\Delta \alpha_{\text {film }}$, when, for a perfect $R^{2}$ fitting with the measured film thickness values, a $\Delta \alpha_{\text {film }}$ of at least $\approx 112 \%$ would be required. This also does not seem to be related to the level of oxidation, because PPAO grease was not or just slightly oxidized. Grease softening, which is often related to contact replenishment [47], may not show significant effects in the case of fully-flooded tests, because replenishment is imposed. This suggests that the film thickness increment is mostly related to additive consumption, which "allowed" for the deposition of thick layers of grease material in the track.

Under starved lubrication, the aged sample of PPAO retained higher film thickness values than the fresh sample. According to Kaneta et al. [47], grease shear degradation results in thicker films due to the suppression of starvation, i.e., softening of the grease will improve its flow, thus improving contact replenishment. Besides, as stated earlier, consumption of additives might allow for the deposition of degraded grease in the track, which also increases film thickness. Aged PPAO also showed high local fluctuations in film thickness values, although lower than the fresh sample. The reduction of local fluctuations in film thickness may also be attributed to thickener degradation [47], which reduces the size of grease material entering the contact.

\section{Conclusions}

The authors' analysis of the film thickness measurements is in agreement with the observations of several authors and adds some important aspects regarding separate film properties in EHL contacts.

Under fully-flooded lubrication, which can be related to the churning phase and the early stages of the bleeding phase in grease-lubricated rolling contacts, it was observed that:

- Bled oil properties and composition might be different than the base oil ones depending on the grease type;

- Grease film thickness cannot be accurately predicted using the base or bled oil properties for some grease types;

- Grease and bled oil generated higher film thickness than the corresponding base oil;

- Grease thin-film measurements at low rolling speeds showed unusually thick films and increasing film values with decreasing speed, contrary to the usual fluid film behavior; such behavior was not observed for base and bled oils, indicating that this is associated with the thickener/co-thickener;

- The speed at which lubricating greases change their trend $\left(U_{h m i n}\right)$ depends on grease formulation, the thickener type and concentration, most likely, being the dominant factors; 
- The grease thicker films observed at low speeds do not contribute to the film thickness at the higher speeds, which approaches the bled oil ones and follow a typical Newtonian trend $\left(h \propto U^{0,67}\right)$.

These results, when analyzed together with a very recent publication $[3,41]$ suggest that the grease mechanism of lubrication under the fully-flooded condition is not solely governed by its oil properties, as has been considered up to the moment. Therefore, the grease film thickness cannot be accurately predicted using the base oil (common practice) or the bled oil properties, as stated by the author in a previous work [2]. This situation demands for better test rigs, which might provide clearer information on the grease lubrication mechanisms, where the thickener type will finally be taken into account.

Under the starved elastohydrodynamic regime, which is the dominant condition that many grease-lubricated rolling contacts operate under after the initial stages of the bleeding phase, it was observed that:

- Film thickness decreases quickly over time, followed by stabilization;

- The stabilized values fluctuate wildly, and the standard deviation is very high, due to very frequent lumps entering the contact;

- The stabilized film probably consist of a liquid layer of bled oil with thickener material passing through the contact;

- Thickeners with more susceptibility to crossing the contact and that contribute the most to locally increase the film thickness follow the order $\mathrm{PP}>\mathrm{Ca}>\mathrm{Li}$.

These results suggest that the grease mechanism of lubrication under starved conditions is initially governed by the bled oil + thickener/co-thickener that passes through the contact. During its passage through the contact, this may be deposited on the surfaces due to the severe conditions in the high pressure zone. The more thickener that passes through the contact, the higher the possibility of thickener deposition and thicker residual layers. Thickener/co-thickener effects on locally increasing the film follow the order of $\mathrm{PP}>\mathrm{Ca}>\mathrm{Li}$. However, as the starved tests were carried out over a very short period of time (30 min), the lubrication mechanisms may change after that. For instance, in cases of severe operating conditions, it is expected that the additives will interact with the surface and change the way that grease performs.

Aged lubricating greases under a fully-flooded and starved EHL regime showed that:

- Aged greases showed higher film thickness values regardless of their level of degradation;

- The highest film thickness of aged greases was attributed to the increase on bled oil viscosity, thickener deposition on the track due to additive consumption, grease rheological changes (softening or hardening) and the formation of oxidation products.

Grease properties vary constantly during operation. Most of the changes to the rheological properties and oil loss occur at the beginning of grease life due to mechanical stress (mostly churning). Chemical changes, such as additive exhaustion and the formation of oxidation products, occur after approximately half of the grease life [48]. All of these changes affect the tribological performance of lubricating greases in a different manner.

From the analysis of the experimental results, it was verified that whatever the physicochemical changes that occurred in the lubricating greases, whilst they are still able to release enough oil to 
replenish the contact and the speed is high enough, bled oil appears to be the active lubricant. As soon as the oil available for lubricating the contact becomes insufficient, such as in situations of thin films or at very low entrainment speeds, the bled oil is no longer the active lubricant, and film formation seems to depend on the grease properties, mostly on the thickener. The different types of active lubricants suggested in the literature are grease materials, degraded or not, deposited in the track (physical absorption) [46] or materials with enhanced viscosity of additives and/or thickeners [49].

Consequently, the greases' capacity to form and sustain thick boundary layers with good lubricity during the later stages of grease lubrication depends mostly on the thickener-additives-surface interaction, plus the hydrodynamic effect generated by the small amounts of bled oil present in the contact.

\section{Acknowledgments}

The authors would like to thank the Fundação para a Ciência e Tecnologia (FCT) of the Portuguese Administration for support given to this study through the research project "Rheology, starvation and tribofilms in grease lubricated rolling bearings" (ref. number PTDC/EME-PME/122271/2010), and through the individual Doctoral Degree Grant "Power loss in grease lubricated rolling bearings" (ref. number SFRH /BD/70684/2010). The authors would also like to thanks Roland Larsson from Luleå University of Technology and Piet Lugt from SKF Engineer and Research Center for providing the means to perform part of the experimental work.

\section{Author Contributions}

Tiago Cousseau wrote the paper and performed most of the result analysis. Beatriz Graç performed some rheological measurements. Armando Campos and Jorge Seabra reviewed the whole work and added significantly to Section 3.

\section{Conflicts of Interest}

The authors declare no conflict of interest.

\section{References}

1. Lugt, P. Grease Lubrication in Rolling Bearings; Tribology Series, John Wiley \& Sons: West Sussex, UK, 2013.

2. Cousseau, T.; Björling, M.; Graça, B.; Campos, A.; Seabra, J.; Larsson, R. Film thickness in a ball-on-disc contact lubricated with greases, bleed oils and base oils. Tribol. Int. 2012, $53,53-60$.

3. Morales-Espejel, G.; Lugt, P.; Pasaribu, H.; Cen, H. Film thickness in grease lubricated slow rotating rolling bearings. Tribol. Int. 2014, 74, 7-19.

4. Bordenet, L.; Dalmaz, G.; Chaomleffel, J.; Vergne, F. A study of grease film thicknesses in elastorheodynamic rolling point contacts. Lubr. Sci. 1990, 2, 273-284. 
5. Kauzlarich, J.J.; Greenwood, J. Elastohydrodynamic lubrication with Herschel-Bulkley model greases. ASLE Trans. 1972, 15, 269-277.

6. Cann, P.; Williamson, B.; Coy, R.; Spikes, H. Behaviour of greases in elastohydrodynamic contacts. J. Phys. D: Appl. Phys. 1992, 25, A124-A132.

7. Yang, Z.; Qian, X. A solution to grease lubricated EHD Film thickness in an Elliptical rolling contact. ImechE Conference Publication 1987, 1, 97-104.

8. Wedeven, L.D.; Evans, D.; Cameron, A. Optical analysis of ball bearing starvation. J. Tribol. 1971, 93, 349-361.

9. Aström, H.; Isaksson, O.; Höglund, E. Video recordings of an EHD point contact lubricated with grease. Tribol. Int. 1991, 24, 179-184.

10. Larsson, P.O.; Larsson, R.; Jolkin, A.; Marklund, O. Pressure fluctuations as grease soaps pass through an EHL contact. Tribol. Int. 2000, 33, 211-216.

11. Cann, P.; Hurley, S. Started Lubrication of EHL Contacts-Relationship to Bulk Grease Properties. NLGI Spokesman 2000, 64, 15-23.

12. Cousseau, T.; Graça, B.; Campos, A.; Seabra, J. Experimental measuring procedure for the friction torque in rolling bearings. Lubr. Sci. 2010, 22, 133-147.

13. SKF Group. SKF General Catalogue 6000; AB SKF: Gothenburg, Sweden, 2005.

14. Yanshuang, W.; Boyuan, Y. An investigation into grease behavior in thermal EHL circular contacts. Tribol. Trans. 2006, 49, 449-453.

15. Lu, X.; Khonsari, M.M. An experimental investigation of grease-lubricated journal bearings. $J$. Tribol. 2007, 129, 84-90.

16. Cousseau, T. Film thickness and friction in grease lubricated contacts. Application to rolling bearing torque loss. PhD Thesis, Faculty of Mechanical Engineering of Porto University, Porto, Portugal, 2013.

17. Cousseau, T.; Graça, B.; Campos, A.; Seabra, J. Friction and wear in thrust ball bearings lubricated with biodegradable greases. Proc. Inst. Mech. Eng. J J. Eng. Tribol. 2011, 225, 627-639.

18. Lundberg, J.; Berg, S. Grease-lubrication of roller bearings in railway waggons. Part 2: laboratory tests and selection of proper test methods. Ind. Lubr. Tribol. 2000, 52, 76-86.

19. Hurley, S.; Cann, P.M.; Spikes, H.A. Lubrication and feflow properties of thermally aged greases. Tribol. Trans. 2000, 43, 9-14.

20. Cann, P.M.; Spikes, H.A.; Hutchinson, J. The development of a spacer layer imaging method (SLIM) for mapping elastohydrodynamic contacts. Tribol. Trans. 1996, 39, 915-921.

21. Hartl, M.; Krupka, I.; Liska, M. Differential colorimetry: Tool for evaluation of chromatic interference patterns. Opt. Eng. 1997, 36, 2384-2391.

22. Jackson, K.D.O. A guide to identifying common inorganic fillers and activators using vibrational spectroscopy. J. Nat. Rubber Res. 1997, 12, 102-111.

23. Zhu, X.; Yan, D.; Fang, Y. In situ FTIR spectroscopic study of the conformational change of isotactic polypropylene during the crystallization process. J. Phys. Chem. B 2001, 105, 12461-12463. 
24. Cann, P.M.; Spikes, H.A. In lubro studies of lubricants in EHD contacts using FTIR absorption spectroscopy. Tribol. Trans. 1991, 34, 248-256.

25. Cann, P.; Webster, M.; Doner, J.; Wikström, V.; Lugt, P. Grease degradation in R0F bearing tests. Tribol. Trans. 2007, 50, 187-197.

26. Akintayo, E.T.; Olaofe, O.; Akintayo, C.O.; Adefemi, C.O. Potential of Fourier transform Infrared spectroscopy for characterising vegetable oils. Int. J. Chem. 2002, 12, 151.

27. Diaby, M.; Sablier, M.; Negrate, A.L.; Fassi, M.E.; Bocquet, J. Understanding carbonaceous deposit formation resulting from engine oil degradation. Carbon 2009, 47, 355-366.

28. Gracia, N.; Thomas, S.; Thibault-Starzyk, F.; Lerasle, O.; Duponchel, L. Combination of mid-infrared spectroscopy and curve resolution method to follow the antioxidant action of alkylated diphenylamines. Chemom. Intell. Lab. Syst. 2011, 106, 210-215.

29. Hurley, S. Fundamental Studies of Grease Lubrication in Elastohydrodynamic Contacts. PhD Thesis, University of London, Imperial College of Science, Technology and Medicine, London, UK, 2000.

30. Cann, P.; Doner, J.; Webster, M.; Wikström, V. Grease degradation in rolling element bearings. Tribol. Trans. 2001, 44, 399-404.

31. Aranzabe, A.; Aranzabe, E.; Marcaide, A.; Ferret, R.; Terradillos, J.; Ameye, J.; Shah, R. Comparing Different Analytical Techniques to Monitor Lubricating Grease Degradation. NLGI Spokesman-Including NLGI Annual Meeting-National Lubricating Grease Institute. National Lubricating Grease Institute: Kansas City, MO, USA, 2006; Volume 70, pp. 17-30.

32. Bley, T.; Pignanelli, E.; Schutze, A. Multichannel IR Sensor System for Determination of Oil Degradation. In Proceeding of 14th International Meeting on Chemical Sensors-IMCS 2012, Nuremberg, Germany, 20-23 May 2012; pp. 974-977.

33. Li, Q.; Jiang, P.; Wei, P. Thermal degradation behavior of poly(propylene) with a novel silicon containing intumescent flame retardant. Macromol. Mater. Eng. 2005, 290, 912-919.

34. Cross, M.M. Rheology of non-Newtonian fluids: A new flow equation for pseudoplastic systems. J. Colloid Sci. 1965, 20, 417-437.

35. Ariff, Z.M.; Ariffin, A.; Jikan, S.S.; Rahim, N.A.A., Polypropylene. Chapter 3-Rheological Behaviour of Polypropylene Through Extrusion and Capillary Rheometry. Intech Open Access Publisher: Slavka Krautzeka, Croatia, 2012; pp. 29-48.

36. Lundberg, J. Grease lubrication of roller bearings in railway waggons. Part 1: Field tests and systematic evaluation to determine the optimal greases. Ind. Lubr. Tribol. 2000, 52, 36-44.

37. Cann, P.M. Starved grease lubrication of rolling contacts. Tribol. Trans. 1999, 42, 867-873.

38. Cousseau, T.; Björling, M.; Graça, B.; Campos, A.; Seabra, J.; Larsson, R. Influence of grease bleed oil on ball-on-disc lubrication. In Proceedings of the 5th World Tribology Congress, Torino, Italy, 8-13 September 2013; p. 4.

39. Larsson, P. Lubricant Replenishment in the Vicinity of an EHD Contact. PhD Thesis, Tekniska högskolan i Luleå, Luleå, Sweden, 1996.

40. Couronné, I.; Vergne, P.; Mazuyer, D.; Truong-Dinh, N.; Girodin, D. Effects of grease composition and structure on film thickness in rolling contact. Tribol. Trans. 2003, 46, 31-36. 
41. Cen, H.; Lugt, P.M.; Morales-Espejel, G. On the film thickness of grease-lubricated contacts at low speeds. Tribol. Trans. 2014, 57, 668-678.

42. Eriksson, P.; Wikström, V.; Larsson, R. Grease passing through an elastohydrodynamic contact under pure rolling conditions. Proc. Inst. Mech. Eng. J J. Eng. Tribol. 2000, 214, 309-316.

43. Cann, P.M.; Williamson, B.P.; Coy, R.C.; Spikes, H.A. The behaviour of greases in elastohydrodynamic contacts. J. Phys. D: Appl. Phys. 1992, 25, A124.

44. Bair, S.; Krupka, I.; Sperka, P.; Hartl, M. Quantitative elastohydrodynamic film thickness of mechanically degraded oil. Tribol. Int. 2013, 64, 33-38.

45. van Zoelen, M.T.; Venner, C.H.; Lugt, P.M. Prediction of film thickness decay in starved elasto-hydrodynamically lubricated contacts using a thin layer flow model. Proc. Inst. Mech. Eng. J J. Eng. Tribol. 2009, 223, 541-552.

46. Cann, P. Grease degradation in a bearing simulation device. Tribol. Int. 2006, 39, 1698-1706.

47. Kaneta, M.; Ogata, T.; Takubo, Y.; Naka, M. Effects of a thickener structure on grease elastohydrodynamic lubrication films. Proc. Inst. Mech. Eng. J J. Eng. Tribol. 2000, 214, 327-336.

48. van den Kommer, A.; Ameye, J. Prediction of remaining grease life-A new approach and method by linear sweep voltammetry. In Proceeding of the 7th TAE International Colloquim Tribology, Esslingen, Germany, 2001; pp. 891-896.

49. Spikes, H.A. Film-forming additives-Direct and indirect ways to reduce friction. Lubr. Sci. 2002, 14, 147-167.

(C) 2015 by the authors; licensee MDPI, Basel, Switzerland. This article is an open access article distributed under the terms and conditions of the Creative Commons Attribution license (http://creativecommons.org/licenses/by/4.0/). 